\title{
Cine, memoria y género, una perspectiva en crecimiento Imaginario social y representación Proyecto de Investigación 14.3 Equipo de Investigación
}

Zulema Marzorati y Mercedes Pombo por Facultad de Diseño y Comunicación, Universidad de Palermo (ARG), y Claudia Bossay por Universidad de Chile (CHI)

Línea de Investigación 14.

Cine y sociedad: Reflexiones sobre el cine contemporáneo

Resultados publicados en el [Cuaderno 95]

Cuaderno del Centro de Estudios de Diseño y Comunicación No95. (2021) Cultura audiovisual, memoria y género. Una perspectiva en movimiento. Coordinación Zulema Marzorati, Mercedes Pombo y Claudia Bossay. Programa de Investigación de la Facultad de Diseño y Comunicación. Centro de Estudios en Diseño y Comunicación. Facultad de Diseño y Comunicación. Universidad de Palermo. Año XXII, Septiembre 2021, Buenos Aires, Argentina. ISSN: 1668-0227.

Los resultados de este Proyecto de Investigación fueron evaluados por Ricardo López León y su Dictamen se transcribe a continuación:

\section{Síntesis de la Evaluación}

Actualidad de la temática (Vigencia, Aplicación) / Notable Nivel Alcanzado (Profundidad, Consistencia, Jerarquía) / Notable

Diversidad del enfoques (Pluralidad, Participación) / Notable

Calidad (Problemática, Análisis, Tratamiento) / Notable

Contribución al avance del Diseño (Fortaleza) / Buena

\section{Fundamentos y Comentarios}

El Cuaderno del Centro de Estudios de Diseño y Comunicación No95, refleja de manera clara los resultados del proyecto de investigación Cine, memoria y género, una perspectiva en crecimiento. A través de sus páginas las investigaciones presentadas ofrecen una perspectiva en la que el cine es visto como testigo, al mismo tiempo que representa un documento histórico como memoria. Así mismo, las perspectivas presentadas proyectan una ampliación del campo de los estudios audiovisuales. 
El documento revisado descubre cómo considerar al cine para el análisis histórico de la representación de la mujer, y así, desde las perspectivas actuales reconocer prácticas de esterotipación que permiten contribuir al campo de los estudios de género. Se abordan películas que, aunque narran situaciones históricas, las problemáticas a las que se enfrentan los personajes siguen siendo actuales y por lo tanto su análisis desde un punto de vista académico resulta necesario. El análisis del rol de la mujer desde la perspectiva histórica a través del cine, permitió a los investigadores presentar también un campo fértil para la incorporación y aplicación de distintas herramientas teóricas y metodológicas que enriquecen el campo de los estudios visuales. Asimismo, la pluralidad del texto se vuelve evidente pues se revisan temas fundamentales como la configuración de la identidad y cómo la misma es abordada desde distintos filmes y narrativas, que van desde conceptos como las mujeres trans, hasta la masculinidad, esta última transformada a partir de nuevas prácticas de paternidad. Estas propuestas representan una discusión y apertura a campos de investigación de los estudios de género, vinculado con los estudios sobre narrativas audiovisuales.

Respecto a los estudios audiovisuales en el documento son visibles propuestas que representan una ampliación en ese campo, como puede ser la relación que se establecen con otras disciplinas performativas, particularmente el teatro, que permite expandir el campo de estudio y proponer nuevas rutas de investigación que enriquecen ambas disciplinas. Asimismo, la investigación contribuye al estudio de los procesos de transducción de las obras literarias a los medios audiovisuales, un esfuerzo que permite comprender las intenciones comunicacionales de las diferencias entre las mismas, así como reflexionar sobre el impacto del rol de género de los intermediarios.

En cuanto a la contribución del avance del diseño, dicha aportación se encuentra un poco más velada y podría hacerse más explícita en la introducción. Es sin duda una aportación al campo de estudio de los fenómenos audiovisuales, pero el vínculo entre este y el diseño podría aclararse. Asimismo, dada la era hipervisual y tecnológica en la que vivimos, se agradecería que los autores mencionaran futuros esfuerzos de investigación sobre el estudio y aproximación a nuevos fenómenos audiovisuales particularmente en el contexto de las redes sociales.

Finalmente, aún y cuando en el documento se discuten aspectos que tienen que ver con la imagen, sorprende la ausencia de las mismas en todo el cuerpo de texto. Sin duda incluir imágenes en algunas de las investigaciones abonaría en la comprensión de los argumentos, además de ser un elemento casi obligado por tratarse de una perspectiva de abordaje audiovisual. 